\section{ABCS}

How to cite this article: Hino et al. Clinical and epidemiological profile of premature patients in the ambulatory of pediatric ophthalmology of a university health service. ABCS Health Sci. 2020;45(Suppl.3):e020102. https://doi. org/10.7322/abcshs.2020S02.1849

Corresponding author: Vagner Loduca Lima - Discipline of Ophthalmology, Centro Universitário FMABC - Avenida Lauro Gomes, 2000 - CEP 09060-870 - Santo André (SP) Brazil - E-mail:vagner@loduca.com.br

Declaration of interests: nothing to declare.

This is an open access article distributed under the terms of the Creative Commons Attribution License

(C) 2020 Hino et al.

\title{
Clinical and epidemiological profile of premature patients in the ambulatory of pediatric ophthalmology of a university health service
}

Fabio Naoki Hino1, Vitório Lauro D’Amico Filho, Jéssica Agena1, Wesley de Paula Duque, Vagner Loduca Lima ${ }^{1}$

${ }^{1}$ Discipline of Ophthalmology, Centro Universitário FMABC - Santo André (SP), Brazil

\begin{abstract}
Introduction: Retinopathy of prematurity (ROP) is a vasoproliferative disorder of the retina that affects low birth weight preterm babies and is the leading cause of blindness in children in developed and developing countries. Objective: Considering the importance of evaluating the pathology, this study aimed to carry out an epidemiological analysis of premature patients referred to the Pediatric Ophthalmology sector of Centro Universitário FMABC. Methods: Retrospective study of the medical records of patients referred to the Pediatric Ophthalmology sector of Centro Universitário FMABC, from March 2017 to December 2017, for ophthalmological evaluation due to suspected ROP (59 medical records). Results: Of the total of 43 eyes with the disease, two eyes fit in Zone II and 41 in Zone III. Seventeen eyes were classified as Stage 1, 16 as Stage 2, 4 as Stage 3, 4 as Stage 4 and 2 as Stage 5. Conclusion: The development of ROP was inversely proportional to weight and gestational age at birth. Treatment proved to be less prevalent in the disease.
\end{abstract}

Keywords: retinopathy; premature; development.

\section{INTRODUCTION}

Retinopathy of prematurity (ROP) is vasoproliferative disorder of the retina that affects low birth weight preterm babies and is the main cause of blindness in children in developed and developing countries ${ }^{1-3}$. Risk factors related to ROP are: birth weight, gestational age and oxygen exposure.

Oxygen plays an important role in ROP. There are two theories of its mechanism of action. The first theory says that there is a delay in the physiological vascular development of the retina that is aggravated by hyperoxia, growth factors and loss of nutrients. The second theory says that vascular proliferation occurs at the junction of the vascularized and avascular retina. The avascular retina produces pro-angiogenic factors, such as vascular endothelial growth factor (VEGF), which is responsible for neovascularization ${ }^{2,4-6}$.

Genetic mutations affecting FZD4, LRP5, TSPAN12 and NDP genes can create a predisposition for the disease. This fact explains why some high-risk patients with extremely low birth weight and gestational age do not develop ROP and others at low risk develop the disease. In addition to investigating genetic variation, epidemiological studies suggest racial and ethnic interference in the incidence of ROP. There was 
an incidence of $7.4 \%$ in white patients with advanced disease and $3.2 \%$ in black patients ${ }^{4}$.

Authors suggest that some molecules are related to the development of ROP, along with biochemical and clinical associations such as VEGF, Insulin-like Growth Factor (IGF-1), erythropoietin and inflammatory markers ${ }^{2}$.

The ROP classification describes three locations (zones I-III), five stages (stage 1-5), and the presence of Plus disease (arteriolar dilation and venous tortuosity $)^{6}$.

The prevention of blindness caused by ROP must be managed quickly, but it depends on an appropriate screening of the risk factors of the disease. The recommendation is that all newborns weighing less than 1,500 g or gestational age less than 30 weeks should be evaluated. The first exam should be performed 4 to 6 weeks after birth or 31 weeks of gestational age, whichever is later. Fundus examination can reveal one of three findings: mature retina, immature retinal vasculature or $\mathrm{ROP}^{6}$.

Although the screening criteria are highly sensitive, less than $10 \%$ of patients with ROP, in developed countries, will need intervention and even with treatment, they will develop visual loss and blindness ${ }^{1,3}$. However, in developing countries, with regional variations in assistance, blindness can reach $40 \% 4$.

The treatment of ROP is based on two main aspects: laser therapy and intra-vitreous injection of anti-VEGF. The study Bevacizumab Eliminates the Angiogenic Threat of Retinopathy of Prematurity treated patients with a single intravitreal injection of Bevacizumab, at a dose of $0.625 \mathrm{mg}$ in $0.025 \mathrm{~mL}$. The study concluded that the proposed treatment reduced the recurrence rate of Stage 3 Zone I ROP when compared to laser. However, they suggest that treatment with Bevacizumab is superior to laser only in Stage 3+ Zone I, but not from Zone $\mathrm{II}^{6}$.

Currently, the number of children requiring evaluation is increasing due to the improved survival of preterm infants, however the number of doctors to perform the examination has not increased $^{1,2}$.

In order to reduce the number of tests and detect children who will need treatment, the WINROP algorithm was developed, which assesses postpartum weight gain, gestational age, birth weight to detect preterm infants with a greater chance of poor evolution ${ }^{6}$

The objective of this study is to carry out an epidemiological analysis of premature patients referred to the Pediatric Ophthalmology sector of the Centro Universitário FMABC.

\section{METHODS}

Retrospective study of the medical records of patients referred to the Pediatric Ophthalmology sector of Centro Universitário FMABC, from March 2017 to December 2017, for ophthalmological evaluation on suspicion of ROP (59 medical records). This study was approved by the Ethics and Research Committee of the Centro Universitário FMABC.

Data such as gender, corrected gestational age at the first exam at the ambulatory of Pediatric Ophthalmology, weight at birth, presence or absence of the disease, classification of the disease and evolution and follow-up of the patient were collected. All information was collected anonymously.

\section{Statistical analysis}

The data were expressed in absolute and relative values (\%), mean and standard deviation. We used the GraphPad Prism software to analyze the data, and the values were considered statistically significant when the $\mathrm{p}$ value $<0.05$.

\section{RESULTS}

We conducted a chart review of 59 patients assisted at Ophthalmology service of the Centro Universitário FMABC. $54 \%$ were male and $46 \%$ female. The corrected gestational age was $43 \pm 6.8$ weeks. About the birth weight, we found 11 patients weighing less than $1,000 \mathrm{~g}, 25$ patients between 1,000 and 1,500 g, 9 patients between 1,500 and 2,000 g, and 14 patients over 2,000 g (Table 1).

Twenty-two patients (37\%) were diagnosed with ROP, in a total sample of 43 eyes. Of these patients, $45 \%$ were female and $55 \%$ were male. The average weight of patients with ROP was $1651 \pm 795 \mathrm{~g}$, whose 9 patients weighing less than $1,000 \mathrm{~g}, 10$ between 1,000 and 1,500 g, 1 between 1,500 and 2000g and 2 above $2,000 \mathrm{~g}$. The corrected gestational age at the time of admission of the patient with the disease was $43 \pm 6.8$ weeks. One patient was less than 30 weeks old, 6 patients between 31 and 40 weeks old, 12 patients between 41 and 50 weeks old, 2 patients between 51 and 60 weeks old and 1 patient between 61 and 70 weeks old (Table 2).

Table 1: Demographic data of patients assisted at the Ophthalmology Service of Centro Universitário FMABC.

\begin{tabular}{|c|c|}
\hline Variables & \\
\hline \multicolumn{2}{|l|}{ Sex } \\
\hline Male & $54 \%$ \\
\hline Female & $46 \%$ \\
\hline $\begin{array}{l}\text { Corrected Gestational Age (GA) } \\
\text { (average } \pm \text { standard deviation) }\end{array}$ & $43 \pm 6,8$ weeks \\
\hline Weight & Number of patients \\
\hline Less than $1,000 \mathrm{~g}$ & 11 \\
\hline 1,000 to $1,500 \mathrm{~g}$ & 25 \\
\hline 1,500 to $2,000 \mathrm{~g}$ & 9 \\
\hline Above $2,000 \mathrm{~g}$ & 14 \\
\hline \multicolumn{2}{|l|}{ ROP diagnosis } \\
\hline Yes & $37 \%$ \\
\hline No & $63 \%$ \\
\hline
\end{tabular}


Table 2: Demographic data of patients assisted at the Ophthalmology Service of Centro Universitário FMABC.

\begin{tabular}{|l|c|}
\hline Variables \\
\hline Sex \\
\hline Male & $55 \%$ \\
\hline Female & $45 \%$ \\
\hline Retinopathy by gestational age & Number of patients \\
\hline Less que 30 weeks & 1 \\
\hline 31 to 40 weeks & 6 \\
\hline 41 to 50 weeks & 12 \\
\hline 51 to 60 weeks & 2 \\
\hline 61 to 70 weeks & 1 \\
\hline Retinopathy by weight of the patient & Number of patients \\
\hline Less than 1,000g & 9 \\
\hline $1,000 g$ to $1,500 \mathrm{~g}$ & 10 \\
\hline $1,500 \mathrm{~g}$ to $2,000 \mathrm{~g}$ & 1 \\
\hline Above $2,000 \mathrm{~g}$ & 2 \\
\hline Classification by zone & Number of eyes \\
\hline Zone I & 0 \\
\hline Zone II & 2 \\
\hline Zone III & 39 \\
\hline Classification by Stage & 17 \\
\hline Stage 1 & 16 \\
\hline Stage 2 & 4 \\
\hline Stage 3 & 4 \\
\hline Stage 4 & 2 \\
\hline Stage 5 & Number of eyes \\
\hline Need for treatment & 4 \\
\hline Yes & 39 \\
\hline No & \\
\hline
\end{tabular}

Of the total of 43 eyes with the disease, two eyes were classified in Zone II and 41 in Zone III. Seventeen eyes were classified as Stage 1, 16 as Stage 2, 4 as Stage 3, 4 as Stage 4 and 2 as Stage 5.
After the first visit, 6 patients did not return for follow-up. Of the other 16 patients with ROP, 2 patients needed treatment. The first patient had both eyes classified as Zone III Stage 4 . They were treated with laser and Bevacizumab. The second patient was classified as Zone III Stage 3 in both eyes and treated with laser only in the right eye. However, the patients did not return after the procedures. The other 16 patients did not require treatment and all had a vascularized retina during follow-up.

\section{DISCUSSION}

Studies on the prevalence of ROP have shown values similar to those found in our study ${ }^{1,6}$.

Reisner et al. ${ }^{7}$ studied 1070 newborns showing a ROP prevalence of $20 \%$ in newborns weighing less than $2,500 \mathrm{~g}, 21 \%$ for weight less than $1,500 \mathrm{~g}$, 35\% for weight less than $1,250 \mathrm{~g}$ and $72 \%$ for weight less than $1,000 \mathrm{~g}$. Literature data show that the occurrence of ROP is mainly associated with low gestational age and birth weight.

Another result of our study that corroborates with the literature is the small number of patients who need interventional treatment. Fortes Filho et al. showed that only $5.3 \%$ of preterm children needed specific treatment ${ }^{8}$.

\section{Conclusion}

Considering the results obtained in this study, we can conclude that the prevalence found here was close to the values found in the literature. The development of ROP was inversely proportional to weight and gestational age at birth. Treatment proved to be less prevalent in the disease.

\section{REFERENCES}

1. Hutchinson AK, Melia M, Yang MB, VanderVeen DK, Wilson LB, Lambert SR. Clinical Models and Algorithms for the Prediction of Retinopathy of Prematurity: A Report by the American Academy of Ophthalmology. Ophthalmology. 2016;123(4):804-16.

https://doi.org/10.1016/j.ophtha.2015.11.003

2. Swan R, Kim SJ, Campbell JP, Chan RVP, Sonmez K, Taylor KD, et al. The genetics of retinopathy of prematurity: a model for neovascular retinal disease. Ophthalmol Retina. 2018;2(9):949-62. https://doi.org/10.1016/j.oret.2018.01.016

3. Quinn GE, Barr C, Bremer D, Fellows R, Gong A, Hoffman R, et al. Changes in course of retinopathy of prematurity from 1986 to 2013: comparison of three studies in the United States. Ophthalmology. 2016;123(7):1595-1600. https://doi.org/10.1016/j.ophtha.2016.03.026

4. Quinn GE. Retinopathy of prematurity blindness worldwide: phenotypes in the third epidemic. Eye Brain. 2016;8:31-6. https://doi.org/10.2147/EB.S94436
5. Pallot C, Faure AS, Charvy C, Ternoy N, Muteau CL, Acar N, et al. Screening for Retinopathy of Prematurity: Insight into Optimizing Screening. Ophthalmic Res. 2018;59(4):228-34. https://doi.org/10.1159/000477622

6. Suelves AM, Shulman JP. Current screening and treatments in retinopathy of prematurity in the US. Eye Brain. 2016;8:37-43. https://doi.org/10.2147/EB.S94439

7. Reisner SH, Amir J, Shohat M, Krikler R, Nissenkorn I, Ben-Sira I. Retinopathy of prematurity: incidence and treatment. Arch Dis Child. 1985;60(8):698-701. https://doi.org/10.1136/adc.60.8.698

8. Fortes Filho JB, Eckert GU, Valiatti FB, Costa MC, Bonomo PP, Procianoy RS. Prevalência e fatores de risco para a retinopatia da prematuridade: estudo com 450 pré-termos de muito baixo peso. Rev Bras Oftalmol. 2009;68(1):22-9. https://doi.org/10.1590/S0034-72802009000100005 